\title{
Q\&A: Sylvia Earle on protecting our seas
}

\author{
Oceanographer and underwater explorer Sylvia Earle served as chief scientist of the US National Oceanic and \\ Atmospheric Administration during 1990-92, and is a US national committee member of the Census of Marine \\ Life, due to conclude this October. Earle advised on Disney's newly released cut of the documentary film Oceans; \\ here she explains why films are important for raising awareness of the state of our seas.
}

\begin{abstract}
What does Oceans show? The documentary was crafted by a team of talented French film-makers headed by Jacques Perrin, who made Microcosmos in 1996 and Winged Migration in 2001. Oceans allows people to experience vicariously what it is like to explore the seas. The film-makers have captured rare behaviours, in some cases contributing to scientific understanding. They used breathtaking techniques to position the cameras in the middle of leaping dolphins, above and under the water, and waited weeks to capture blue whales feeding.
\end{abstract}

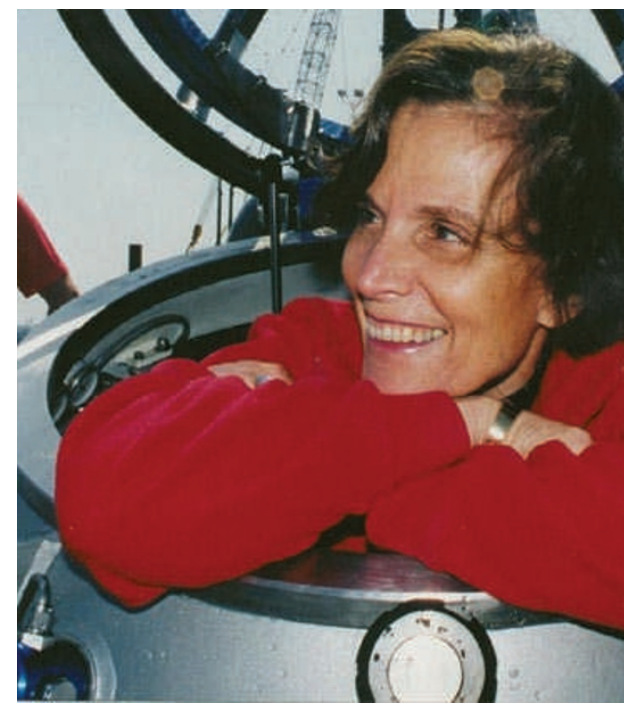

seal. We have watched the serious decline of about half of the coral reefs, plus bluefin tuna, whales, swordfish and marlin. The oceans are our life-support system: they shape climate and weather, drive planetary chemistry and generate most of the oxygen in the atmosphere. The oceans are changing in ways that are not in our favour, possibly more in the past half-century than during all of human history, and we are the agents of that change.

\section{Having consulted on the making of Oceans, the Census of Marine Life recently chose not to associate itself with the Disney cut. Why?}

The French version gives more attention to the message that the ocean is in trouble. The Disney cut has a fuller narration, and some of the scenes that could be troubling to children - such as that of an animatronic shark having its fin cut off for shark-fin soup - have been taken out. It is sophisticated enough to entertain adults, but clear enough for a family audience. It would have been nice to have had one version that the whole world could see, as with Blue Planet in 1990. But some films, such as March of the Penguins in 2005, are recut for a different market. If the census wishes to distance itself from Disney's version of Oceans, that is its right. My personal focus is on celebrating

\section{Is the film right to take a conservationist tone?}

Yes. Since I started exploring oceans in the 1950s, we have seen the collapse of many populations of ocean wildlife - fish, oysters, clams, lobsters - and the extinction of some species, notably the Caribbean monk the magnificent production of images that will move people towards caring about the ocean.

\section{What is the goal of the} Census of Marine Life? To document all forms of life in the seas. What started a decade ago as the Census of Fishes has now recorded more than 200,000 marine species. Thousands of scientists around the world have been diving into museum collections of marine specimens and making undersea expeditions. Even so, less than $5 \%$ of the ocean has been seen, let alone explored to look for life. There may be 40 million forms of life in the sea, not counting 6. the bacteria. Nearly all the major divisions of
life are there. Every dive I take is like diving into the history of life on Earth.

\section{Is the deep sea best explored by people or unmanned probes?}

There is no substitute for the human presence. It has been 50 years since people went to the deepest part of the sea, 10 kilometres down in the Mariana Trench in the Pacific Ocean, and they were there for only half an hour. I want transparent deep-water submarines to take scientists, policy-makers, teachers and poets to the bottom of the sea. We need new materials that can withstand the pressure at those depths but still allow visibility. The Woods Hole Oceanographic Institution in Massachusetts recently built a robotic device, Nereus, that has now gone to full ocean depth. But if you want the most information in the least amount of time, send a human.

\section{What remains unknown about the seas?}

One big missing link is their role in the carbon cycle. The oceans, where most of Earth's carbon is stored, are known to regulate temperature for the planet. Climate discussions are just beginning to acknowledge this issue.

Jascha Hoffman is a writer based in

San Francisco, California.

e-mail: jascha@jaschahoffman.com 